IZA DP No. 9052

\title{
Prepregnancy Obesity and Birth Outcomes
}

Susan L. Averett

Erin K. Fletcher

May 2015 


\title{
Prepregnancy Obesity and Birth Outcomes
}

\author{
Susan L. Averett \\ Lafayette College \\ and IZA \\ Erin K. Fletcher \\ Harvard Kennedy School of Government
}
Discussion Paper No. 9052
May 2015

IZA
P.O. Box 7240
53072 Bonn
Germany

Phone: +49-228-3894-0

Fax: +49-228-3894-180

E-mail: iza@iza.org

\begin{abstract}
Any opinions expressed here are those of the author(s) and not those of IZA. Research published in this series may include views on policy, but the institute itself takes no institutional policy positions. The IZA research network is committed to the IZA Guiding Principles of Research Integrity.

The Institute for the Study of Labor (IZA) in Bonn is a local and virtual international research center and a place of communication between science, politics and business. IZA is an independent nonprofit organization supported by Deutsche Post Foundation. The center is associated with the University of Bonn and offers a stimulating research environment through its international network, workshops and conferences, data service, project support, research visits and doctoral program. IZA engages in (i) original and internationally competitive research in all fields of labor economics, (ii) development of policy concepts, and (iii) dissemination of research results and concepts to the interested public.
\end{abstract}

IZA Discussion Papers often represent preliminary work and are circulated to encourage discussion. Citation of such a paper should account for its provisional character. A revised version may be available directly from the author. 
IZA Discussion Paper No. 9052

May 2015

\section{ABSTRACT \\ Prepregnancy Obesity and Birth Outcomes}

We investigate the association between prepregnancy obesity and birth outcomes using fixed effect models comparing siblings from the same mother. A total of 7,496 births to 3,990 mothers from the National Longitudinal Survey of Youth 1979 survey are examined. Outcomes include macrosomia, gestational length, incidence of low birthweight, preterm birth, large and small for gestational age (LGA, SGA), c-section, infant doctor visits, mother's and infant's days in hospital post-partum, whether the mother breastfed, and duration of breastfeeding. Association of income outcomes with maternal pre-pregnancy obesity was examined using Ordinary Least Squares (OLS) regression to compare across mothers and fixed effects to compare within families. In fixed effect models we find no statistically significant association between most outcomes and prepregnancy obesity with the exception of LGA, SGA, low birth weight and preterm birth. We find that prepregnancy obesity is associated with a with lower risk of low birthweight, SGA, and preterm birth but controlling for prepregnancy obesity, increases in GWG lead to increased risk of LGA. Contrary to previous studies, which have found that maternal obesity increases the risk of c-section, macrosomia and LGA, while decreasing the probability of breastfeeding, our sibling comparison models reveal no such association. In fact, our results suggest a protective effect of obesity in that women who are obese prepregnancy have longer gestation lengths, and are less likely to give birth to a preterm or low birthweight infant.

JEL Classification: $\quad$ I12, J13

Keywords: infant health, birth outcomes, BMI, maternal obesity, gestational weight gain

Corresponding author:

Susan Averett

Department of Economics

Lafayette College

Easton, PA 18042

USA

E-mail: averetts@lafayette.edu 


\section{Introduction}

One in three adults in the U.S. are obese (1) so it is not surprising that obesity is becoming the most common complication of pregnancy (2-3) and the predominant risk factor for maternal mortality in developed countries (4). Women who are obese prior to pregnancy may suffer poor health before, during, and after pregnancy, which may affect their birth outcomes as well as their willingness or ability to breastfeed. An increasing awareness of the potential adverse consequences of maternal obesity during pregnancy has led to repeated updating of the Institute of Medicine (IOM) pregnancy weight gain recommendations (5).

One explanation for the link between birth weight outcomes and maternal prepregnancy obesity is the fetal origins hypothesis, which posits that prepregnancy obesity and excess gestational weight gain (GWG) deliver greater concentrations of glucose and fatty acids to the developing fetus. The resulting increase in fetal insulin accelerates fetal growth and leads to high birth weights, which may be associated with complications at birth (6-8).

Consistent with this hypothesis, obese mothers have been shown to give birth to macrosomic babies (9-11), which places both mother and baby at risk for birth trauma (3). They are also more likely to give birth by c-section (12-16). Obese women are at greater risk for medically induced preterm birth $(2,17)$ and women who are obese prepregnancy are less likely to initiate breastfeeding and breastfeed for shorter durations (18). However, these findings should be viewed cautiously because they are often based on cross-sectional comparisons across births. Thus, they may be biased by hard-to-measure factors such as shared genetics between a 
mother and her baby or other factors that may affect both infant health and prepregnancy obesity.

In this research we examine how prepregnancy obesity and GWG affect birth outcomes, infant health, and breastfeeding initiation and duration. Using data from the National Longitudinal Study of Youth 1979 survey (NLSY79), we compare siblings by estimating mother fixed-effect (FE) models, which allow us to control for unobservable maternal specific factors that may be associated both with prepregnancy obesity and birth outcomes.

\section{Methods}

\section{Data and Key Variables}

We use the NLSY79 cohort for our analysis. The NLSY79 is a nationally representative survey of 12,686 individuals between the ages of 14 and 21 in 1979. Interviews were conducted annually until 1994 and subsequent interviews were conducted every other year up to 2010 when respondents were aged 45-53. Data and data dictionary are available online. Respondents reported data on their labor market experience, births, and marriages every survey round. The NLSY79 also collected information on the height and weight of respondents. Height was collected in 1985 and 2006, while weight was collected almost every round. We observe complete fertility histories for nearly all women in the sample with $99.97 \%$ of births observed by 2000 . These data do not provide a nationally representative sample of children or young adults, although they are representative of the population of children born to U.S. women aged 14-22 in 1979 (19-20). 


\section{Mother's Prepregnancy BMI}

Mother's self-reports of weight and height are used to calculate prepregnancy Body Mass Index (BMI), given by weight (kg) divided by height-squared (meters). Though there is potential for these self-reported measures to be systematically misreported, Goodman et al. (21) show that own reports of weight and height are highly correlated with height and weight measured by a trained enumerator. We then assign respondents to one of four categories using the World Health Organization Cutoffs. Underweight corresponds to a BMI of less than or equal to 18.5 , BMI in the recommended range is between 18.5 and 24.9 inclusive, overweight women are those with a BMI ranging from 25 to 29.9 inclusive, and obese women have a BMI greater than or equal to 30 . GWG is given by mother's report of weight change during pregnancy.

\section{At-birth Outcomes}

We examine several measures of birth weight: macrosomia (birth weight in excess of 9.92 pounds) (22-23); large for gestational age (LGA); small for gestational age (SGA); and whether the baby was low birth weight (5.5 lbs at birth or less). We calculate LGA and SGA using mother's self reports of child birth weight and gestational age combined with US national reference data, using separate cutoffs for boys and girls (24). We also examine how many days the infant spent in the hospital post-birth, whether the infant was born prematurely (before 37 weeks), and how many times the infant was taken to the doctor for an illness during the first year of life. As a post-natal investment, we examine whether or not the mother breastfed and, conditional on breastfeeding, how many weeks she breastfed. Finally, we 
examine c-section birth as obese women are thought to be at higher risk for a csection birth, which may result in adverse health consequences for both mother and infant (25).

\section{Sample}

We observe 9,563 births to women in the NLSY79 between 1979 and 2010. In the first survey after each pregnancy, women report their weight before and at delivery, birth weight of the child, mode of delivery, and weeks of gestation. We exclude 1,952 women with missing information on height or weight or implausible Body Mass Index (BMI) values (less than 15 or greater than 60). We drop observations with reported birth weight in excess of 13 lbs ( 4 dropped), or less than 32 ounces (22 dropped) and those with a gestational age greater than 44 weeks (75 dropped) as is common in this literature (12). We exclude women who gave birth after the age of 40 (none of these 14 women was obese) and an additional three women who did not report marital status or education. ${ }^{\text {a }}$ Our final sample consists of 7,496 singleton births occurring between 1979 and 2004. Of these 7,496 births, 1,604 mothers have one birth in the sample, 1,549 have two births in the sample, 612 have three, 172 have four, 32 have five, 12 have six, and three have seven births. ${ }^{b}$

\section{Data Analysis}

Using the sample of mothers with singleton births over the period 1979-2004, we test whether prepregnancy BMI and GWG are correlated with adverse birth outcomes by estimating Ordinary Least Squares (OLS) regression models. The primary explanatory variables of interest are prepregnancy BMI category and GWG. We control for potential confounding factors including mother's education, race, age 
at first birth, marital status, age at the current birth, parity, smoking status, use of alcohol and prenatal vitamins, and month of first prenatal visit. The models also include a control for child gender and a linear time trend to capture changes in birth technology or medical care over time common to all mothers. In the specifications for c-section we control for whether the mother had a previous c-section. When infant days in hospital is the outcome, weeks of gestation is included as a control since preterm infants often require extra care.

Despite this rich set of covariates, it is likely that the prepregnancy BMI and GWG coefficients are biased due to genetics and other hard-to-measure maternal characteristics. Thus, as noted earlier, we also estimate maternal fixed-effect (FE) models that compare biological siblings.

\section{Results}

\section{Descriptive Results}

Table 1 presents unweighted sample means/proportions for our outcome variables and prepregnancy weight measures for the full sample of mothers and then by prepregnancy BMI. Overall, 22 percent of the births were via c-section, 9 percent were LGA, 17 percent were SGA, 2 percent were macrosomic, 9 percent were low birth weight, and 12 percent were premature, defined as before 37 weeks of

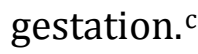

Infants whose mothers were obese before pregnancy were more likely to be born via c-section and to be macrosomic or LGA, and less likely to be SGA, low birth weight, or premature as compared to mothers whose prepregnancy BMI was in the 
recommended range. Mothers who were obese prepregnancy weigh more at the delivery of their child but do not gain as much weight as women in other prepregnancy BMI categories. Infants born to overweight and obese mothers experience more doctor visits for illness in the first year of life and, conditional on breastfeeding, they are breastfed for a shorter duration.

Table 2 presents the unweighted means/proportions of our control variables. Older women and those with more children tend to have higher prepregnancy BMI. Hispanic women represent the smallest share of obese mothers (16\%). Women who are obese are more likely to have a previous c-section.

\section{OLS Results}

Tables 3 and 4 present the OLS models that include the full set of control variables although the coefficients on controls are not shown. Results in Table 3 reveal strong positive correlations between prepregnancy obesity and the outcomes weeks of gestation and LGA $(\mathrm{P}<.01)$, controlling for GWG. We find a weak association between prepregnancy obesity and the probability of macrosomia $(\mathrm{P}<.10)$, controlling for GWG. We find negative associations between prepregnancy obesity and the outcomes low birth weight $(\mathrm{P}<.01)$, SGA $(\mathrm{P}<.01)$, and preterm birth $(\mathrm{P}<.10)$, controlling for GWG. The effect sizes are not trivial. For example, prepregnancy obesity is associated with 7.6 percentage point (ppt) higher probability of LGA, corresponding to an 84.4 percent $((7.6 / 9.0) * 100)$ higher incidence of LGA. In addition, each additional pound gained in pregnancy by mothers who begin their pregnancy obese increases the probability of having an LGA infant by $0.3 \mathrm{ppt}$ $(\mathrm{P}<.01)$. 
Estimates in table 4 indicate that women who are obese prepregnancy are $8.2 \mathrm{ppt}$ more likely to have a c-section $(\mathrm{P}<.01)$ and, conditional on initiating breastfeeding, they breastfeed for 3.8 fewer weeks than their non-obese counterparts $(\mathrm{P}<.01)$. Children whose mothers begin pregnancy obese have more doctor visits for illness in the first year of life $(\mathrm{P}<.05)$.

\section{Mother FE RESULTS}

The most stringent test of the hypothesis that maternal weight affects the outcomes of interest occurs when we include maternal FEs, limiting comparisons to within rather than across mothers (Table 5). These models require that the women in the sample have had more than one birth, so the sample size is reduced $(\mathrm{N}=5,892)$. The effects of prepregnancy obesity are identified off of discordant siblings, i.e., siblings whose mothers changed prepregnancy BMI category across pregnancies $(\mathrm{N}=2,166)$. Obesity is a persistent weight status; nearly 88 percent of women who are obese in the first pregnancy we observe are also obese in the last pregnancy we observe. No women who start their first observed pregnancy obese transition to underweight by the last pregnancy observed. The reverse is true as well: none of the women who are underweight at the time of the first pregnancy we observe are obese at their last pregnancy.

Once controlling for maternal fixed effects, many of the correlations estimated in Table 3 disappear. For example, the top panel of Table 5 shows no effect of prepregnancy obesity on macrosomia or LGA. The results in Table 5 reveal that starting pregnancy obese may exert a protective effect in that these mothers are significantly less likely to have a low birth weight $(\mathrm{P}<.01)$ or SGA baby $(\mathrm{P}<.01)$. They 
also have longer gestation lengths $(\mathrm{P}<.05)$ and are less likely to have a preterm birth $(\mathrm{P}<.05)$. Comparing Table 4 to the bottom panel of Table 5, there is no longer a significant association between prepregnancy obesity and any of the outcomes.

We also run our OLS regressions using the full set of control variables on the sub-sample of women with more than one birth used to estimate the maternal FE and find results qualitatively similar to results on the full sample. Therefore, we conclude that it is the addition of the mother FEs and not the change in sample composition that is responsible for the differences across the OLS and mother FE models that we observe. This further underscores that controlling for unobservable, maternal specific factors is important.

\section{Discussion}

Our results, while largely confirming the findings of prior studies when we use OLS, differ from previous research when we compare siblings, a method which renders some of the associations between prepregnancy obesity and adverse birth outcomes insignificant. Specifically, using maternal FE, we do not find an effect of prepregnancy obesity on the probability of a c-section birth, macrosomia, duration of post-partum hospital stays, or duration of breastfeeding. We do find that maternal prepregnancy obesity is still associated with a lower probability of a preterm birth, low birth weight, and SGA. Similar to Ludwig and Currie (7) and Lawlor et al.,(8) who also make sibling comparisons, we find that controlling for prepregnancy BMI, increased GWG leads to a higher probability of an infant who is LGA in the maternal FE models. 
In contrast to others, we find no effect of maternal prepregnancy obesity on preterm birth (17). However, previous work on this topic has focused on preterm births that were medically induced and our data do not identify preterm births that are medically induced thus our results are not directly comparable.

Many of the outcomes we consider, such as breast-feeding, low birthweight, macrosomia, and preterm birth have been linked to children's cognitive ability, future income and/or educational attainment, highlighting the potential long-term consequences of the outcomes we study (26-34). Furthermore, prepregnancy obesity itself has been linked directly to children's cognitive ability (35). Other outcomes, such as the probability of a c-section and preterm birth, are linked to higher medical costs as well as complications for the mother and infant (36).

The current study has several strengths. First, there are only two papers that we are aware of that use maternal FE to examine associations between prepregnancy obesity and infant outcomes. Ludwig and Currie (7) use a sample containing all births in Michigan and New Jersey from 1989 to 2003 to examine the effect of maternal GWG on infant birth weight. They report that maternal weight gain during pregnancy is associated with increased birth weight. However, they do not have information on the mother's prepregnancy weight, a key control we include. Lawlor et al. (8) explore the effect of GWG on birth weight. Their sibling comparisons, using a sample from Sweden, reveal that women who gained excessive weight in pregnancy have larger babies. However, they lack a good measure of GWG. Instead, they compare pre-delivery weight with the mother's weight at her first antenatal doctor visit. 
A second strength of this study is that we examine a wide array of infant health and at birth outcomes using a large sample that spans the entire U.S. and contains a rich array of control variables. One possible drawback of these measures is that they are self-reported and subject to recall error.

Another limitation of our study is that we cannot control for unobservable, time-variant, mother-specific characteristics. For instance, if mothers who changed weight categories from one pregnancy to the next were aware of the dangers associated with excess weight gain or low prepregnancy BMI they may have engaged in compensatory behavior to counteract the potential adverse effects of their prepregnancy weight status. Or, if there was an unobserved random stressor that caused the mother to change prepregnancy BMI category, it potentially could have affected the birth outcome as well, rendering the association between the birth outcome and BMI category spurious. We cannot observe or control for these compensating behaviors and random events, so if they are systematic, they may bias our maternal FE results.

Overall, our findings suggest that the relationship between prepregnancy obesity and adverse birth outcomes is complex and merits further exploration by researchers. 


\section{References}

1. OECD, Obesity Update, June 2014. Available at: http://www.oecd.org/els/health-systems/Obesity-Update-2014.pdf. Last accessed June 22, 2014.

2. McDonald SD, Han Z, Mulla S, Beyene J. Overweight and obesity in mothers and risk of preterm birth and low birth weight infants: systematic review and meta-analyses. BMJ: British Medical J. 2010, pp.341-359.

3. Lu GC, Rouse DJ, DuBard M, Cliver S, Kimberlin D, Hauth JC. The effect of increasing prevalence of maternal obesity on perinatal morbidity. Am J Obstetrics and Gynecology, October, 2001, pp.845-849.

4. Rowlands I, Graves N, De Jersey S, McIntyre HD, Callaway L. Obesity in pregnancy: outcomes and economics. Seminars in Fetal and Neonatal Medicine 2001;15:2:94-99. WB Saunders.

5. Institute of Medicine (US) and National Research Council (US) Committee to Reexamine IOM Pregnancy Weight Guidelines; Rasmussen KM, Yaktine AL, editors. Weight Gain During Pregnancy: Reexamining the Guidelines. Washington (DC): National Academies Press (US); (2009.) Summary. Available from: http://www.ncbi.nlm.nih.gov/books/NBK32799/

6. Catalano PM. Obesity and Pregnancy - the Propagation of a Viscous Cycle? J of Clin Endocrinology and Metabolism, 2003;88:8.

7. Ludwig DS, Currie J. The association between pregnancy weight gain and birth weight: a within-family comparison. Lancet. 2010;376:9745: 984-90. 
8. Lawlor DA, Lichtenstein P, Fraser A, Långström N. (2011). Does maternal weight gain in pregnancy have long-term effects on offspring adiposity? A sibling study in a prospective cohort of 146,894 men from 136,050 families. The Am J Clin Nutr. 2001; 94:1:142-148.

9. Ehrenberg HM, Mercer BM, Catalano PM. "The influence of obesity and diabetes on the prevalence of macrosomia." Am J Obstetrics and Gynecology, 2004;191: 964-8.

10. Siega-Riz A M, Laraia B. The implications of maternal overweight and obesity on the course of pregnancy and birth outcomes. Mater Child Health J. $2000 ; 10(1) 153-156$.

11. Yu Z, Han S, Zhu J, Sun X, Ji C, Guo X. Prepregnancy Body Mass Index in Relation to Infant Birth Weight and Offspring Overweight/Obesity: A Systematic Review and Meta-Analysis. PLoS ONE . 2013;8:4: e61627. doi:10.1371/journal.pone.0061627

12. Margerison-Zilko C, Rehkopf D, Abrams B. Association of maternal gestational weight gain with short- and long-term maternal and child health outcomes." Am J Obstetrics and Gynecology. 2010;202:574, e.1-8.

13. Thompson LA, Zhang S, Black E, Das R, Ryngaert M, Sullivan S, Roth, J. (2013). The association of maternal prepregnancy body mass index with breastfeeding initiation. Mater Child Health J, 2013;17(10): 1842-1851.

14. Mamun, A. A., Callaway, L. K., O'Callaghan, M. J., Williams, G. M., Najman, J. M., Alati, R., ... \& Lawlor DA. Associations of maternal prepregnancy obesity and 
excess pregnancy weight gains with adverse pregnancy outcomes and length of hospital stay. BMC pregnancy and childbirth. 2011; 11(1);62.

15. Nohr EA, Vaeth M, Baker JL, Sorensen TA, Olsen J, Rasmussen KM. Combined associations of prepregnancy body mass index and gestational weight gain with the outcome of pregnancy. Am J Clin Nutr. 2008; 87: 170-1759.

16. Weiss J. Malone FD, Emig D, Ball RH, Nyberg DA, Comstock CH, Saade G, Eddleman K, Carter SM, Craigo SD, Carr SR, D'Alton ME. Obesity, obstetric complications and cesarean delivery rate-A population-based screening study. Am J Obstetrics and Gynecology. 2004;190: 1091-1097.

17. Cnattingius S, Villamor E, Johansson S, Bonamy AKE, Persson M, Wikström AK, Granath F. (2013). Maternal obesity and risk of preterm delivery. J Am Med Assoc. 2013; 309(22):2362-2370.

18. Hauff LE, Leonard SA, Rasmussen KM. Associations of maternal obesity and psychosocial factors with breastfeeding intention, initiation, and duration. Am J Clin Nutr. 2014; ajcn-071191.

19. Baker P, Keck C, Mott F, Quinlan S. NLSY child handbook: A guide to the NLSY child data. Columbus: Center for Human Resource Research, Ohio State University. 1993.

20. Wu, LL,Allen Li JC. Children of the NLSY79: a unique data resource. Monthly Labor Review. 2005;128:59-62.

21. Goodman E, Hinden BR, Khandelwal S. Accuracy of Teen and Parental Reports of Obesity and Body Mass Index. Pediatrics. 2003;106:52-58. 
22. Stotland, N. E., A. B. Caughey, E. M. Breed, \& G. J. Escobar, (2004). “Risk factors and obstetric complications associated with macrosomia." International J of Gynecology \& Obstetrics. 2004;87(3);220-226.

23. American College of Obstetricians and Gynecologists. Fetal macrosomia. ACOG Practice Bulletin 22. Washington (DC): ACOG; 2000. p. 1-11.

24. Oken E, Kleinman KP, Rich-Edwards J, Gillman M. A nearly continuous measure of birth weight for gestational age using a United States national reference." BMC Pediatrics. 2003; 3(6), doi:10.1186/1471-2431-3-6

25. MacDorman MF, Menacker F, Declercq E. Cesarean birth in the United States: epidemiology, trends, and outcomes. Clinics in perinatology. 2008;35(2):293307.

26. Oddy WH, Li J, Whitehouse AJ, Zubrick SR, Malacova E. Breastfeeding duration and academic achievement at 10 years. Pediatrics. 2011;127(1): e137-e145.

27. Yang S, Platt RW, Kramer MS. Variation in child cognitive ability by week of gestation among healthy term births. Am J Epidemiology. 2010: kwp413.

28. Noble KG, Fifer WP, Rauh VA, Nomura Y, Andrews HF. Academic achievement varies with gestational age among children born at term. Pediatrics. 2012;130(2): e257-e264.

29. Conley D, Bennett NG. Birth weight and income: interactions across generations." J Health and Social Behavior. 2001; 450-465.

30. Case A, Fertig A, Paxson C. The lasting impact of childhood health and circumstance. J Health Econ. 2005;24(2):365-389. 
31. Rees DI, Sabia JJ. The Effect of Breastfeeding on Educational Attainment:

Evidence from Sibling Data. University of Colorado Working Paper No. 09-03. 2009.

32. Cesur R, Kelly IR. From cradle to classroom: high birth weight and cognitive outcomes. Health Econ, 2010;13(2).

33. Cheadle JE, Goosby BJ. Birth weight, cognitive development, and life chances: A comparison of siblings from childhood into early adulthood. Soc Sci Res. 2010;39(4):570-584.

34. Colen CG, Ramey DM. Is Breast Truly Best? Estimating the Effects of Breastfeeding on Long-term Child Health and Wellbeing in the United States Using Sibling Comparisons. Soc Sci Med. 2014;109:55-65.

35. Tanda, R., Salsberry, P. J., Reagan, P. B., \& Fang, M. Z. (2013). The impact of prepregnancy obesity on children's cognitive test scores. Maternal and child health journal, 17(2), 222-229.

36. Huynh L, McCoy M, Law A, Tran KN, Knuth S, Lefebvre P, Sullivan S, Duh MS. Systematic Literature Review of the Costs of Pregnancy in the US. PharmacoEconomics, 2013;31(11):1005-1030.

\footnotetext{
${ }^{\text {a }}$ As is common in survey data, a significant number of women do not report their income. Rather than exclude them from our analysis, we measure income categorically including a category for missing. Categories are then adjusted for inflation.

b Although the NLSY does not ask directly about gestational diabetes, respondents are asked retrospectively if they have ever been diagnosed with diabetes. We match that with information on her child's year of birth and identified 46 women who were diagnosed with diabetes when they would have been pregnant. If we omit these women from our analysis, as Ludwig and $\mathrm{Currie}^{7}$ do, our results are virtually identical.
} 
c Although the rate of c-section observed in the sample is lower than the current national rate of approximately 33 percent, recall that our data are observed from 1979 to 2004 . Our annual c-section rates do increase over time similar to those in the U.S. over this period. 
Table 1:

Unweighted sample means/proportions for infant outcome variables by mother's prepregnancy BMI

category

\begin{tabular}{lrrrrr}
\hline Variable & All Mothers & BMI $<\mathbf{1 8 . 5}$ & BMI 18.5-24.9 & BMI 25.0-29.9 & \multicolumn{1}{c}{ BMI > 30 } \\
\hline LGA & 0.09 & 0.04 & 0.08 & 0.10 & 0.14 \\
SGA & 0.17 & 0.24 & 0.17 & 0.14 & 0.12 \\
Macrosomic & 0.02 & 0.01 & 0.02 & 0.02 & 0.03 \\
C-section & 0.22 & 0.15 & 0.21 & 0.27 & 0.34 \\
Low birth weight & 0.09 & 0.14 & 0.08 & 0.07 & 0.07 \\
Born before 37 weeks & 0.12 & 0.18 & 0.12 & 0.11 & 0.11 \\
Weeks of gestation & 38.62 & 38.20 & 38.65 & 38.66 & 38.75 \\
& $(2.13)$ & $(2.43)$ & $(2.11)$ & $(2.05)$ & $(1.99)$ \\
\# dr. visits infant year 1 & 1.76 & 1.68 & 1.71 & 1.89 & 1.99 \\
& $(3.77)$ & $(3.77)$ & $(3.47)$ & $(4.70)$ & $(3.96)$ \\
\# days mom hosp & 3.45 & 3.65 & 3.41 & 3.44 & 3.51 \\
& $(3.70)$ & $(4.06)$ & $(3.77)$ & $(3.51)$ & $(2.96)$ \\
Mom breastfed & 0.47 & 0.42 & 0.49 & 0.44 & 0.43 \\
\# wks breastfed & 18.84 & 19.12 & 19.10 & 18.41 & 16.99 \\
& $(21.13)$ & $(21.59)$ & $(21.12)$ & $(21.51)$ & $(19.79)$ \\
\# days infant hosp. postpartum & 4.46 & 5.72 & 4.37 & 4.14 & 4.35 \\
& $(8.75)$ & $(17.73)$ & $(7.50)$ & $(5.83)$ & $(6.63)$ \\
GWG & 31.60 & 32.61 & 32.35 & 30.48 & 26.65 \\
& $(14.30)$ & $(14.55)$ & $(13.71)$ & $(14.78)$ & $(16.51)$ \\
Mom's BMI & 23.06 & 17.52 & 21.46 & 26.91 & 34.47 \\
& $(4.62)$ & $(0.73)$ & $(1.70)$ & $(1.41)$ & $(4.46)$ \\
Observations & 7496 & 697 & 4937 & 1261 & 601 \\
\hline
\end{tabular}

Sample means/proportions. Standard deviations for continuous variables in parentheses. 
Table 2: Unweighted sample means/proportions of control variables by mother's prepregnancy BMI

\begin{tabular}{|c|c|c|c|c|c|}
\hline Variable & All Mothers & $\mathrm{BMI}<18.5$ & BMI 18.5-24.9 & BMI 25.0-29.9 & BMI $>30$ \\
\hline Not black/Hispanic & 0.54 & 0.59 & 0.57 & 0.46 & 0.48 \\
\hline Hispanic & 0.19 & 0.17 & 0.18 & 0.23 & 0.16 \\
\hline Black & 0.27 & 0.25 & 0.25 & 0.31 & 0.36 \\
\hline Child is male & 0.51 & 0.52 & 0.51 & 0.52 & 0.49 \\
\hline \multirow[t]{2}{*}{ Mom's age at first birth } & 21.95 & 20.53 & 21.98 & 22.24 & 22.72 \\
\hline & $(4.58)$ & (3.88) & (4.59) & (4.56) & (4.90) \\
\hline \multirow[t]{2}{*}{ Mom's age at birth of child } & 25.08 & 22.99 & 24.91 & 26.00 & 27.04 \\
\hline & $(4.76)$ & $(4.48)$ & $(4.71)$ & (4.59) & $(4.71)$ \\
\hline \multirow[t]{2}{*}{ Birth order } & 1.94 & 1.78 & 1.89 & 2.11 & 2.18 \\
\hline & $(1.07)$ & $(1.01)$ & $(1.04)$ & $(1.17)$ & $(1.14)$ \\
\hline \multirow{2}{*}{ Child birth year } & 1986.14 & 1984.31 & 1985.89 & 1987.05 & 1988.37 \\
\hline & $(4.70)$ & $(4.16)$ & $(4.61)$ & $(4.77)$ & $(4.76)$ \\
\hline \multirow[t]{2}{*}{ Mom's yrs of education } & 12.27 & 11.61 & 12.36 & 12.31 & 12.24 \\
\hline & (2.37) & (2.23) & (2.38) & $(2.41)$ & (2.18) \\
\hline Mother is married & 0.67 & 0.58 & 0.67 & 0.70 & 0.65 \\
\hline Mother is sep./div./wid. & 0.08 & 0.09 & 0.08 & 0.08 & 0.09 \\
\hline Low Income & 0.26 & 0.36 & 0.25 & 0.27 & 0.26 \\
\hline Middle Income & 0.28 & 0.26 & 0.27 & 0.29 & 0.35 \\
\hline Urban residence & 0.74 & 0.72 & 0.74 & 0.74 & 0.74 \\
\hline \multirow[t]{2}{*}{ Month of first prenatal visit } & 2.58 & 2.62 & 2.57 & 2.57 & 2.62 \\
\hline & (1.63) & (1.56) & $(1.60)$ & (1.71) & (1.74) \\
\hline Took prenatal vitamins & 0.90 & 0.88 & 0.90 & 0.90 & 0.91 \\
\hline \multirow[t]{2}{*}{ Used alc. in preg. $<1$ per month } & 0.23 & 0.23 & 0.25 & 0.21 & 0.19 \\
\hline & $(0.42)$ & $(0.42)$ & $(0.43)$ & $(0.40)$ & $(0.40)$ \\
\hline \multirow[t]{2}{*}{ Used alc. monthly during preg. } & 0.04 & 0.04 & 0.04 & 0.04 & 0.03 \\
\hline & $(0.20)$ & $(0.20)$ & $(0.20)$ & $(0.20)$ & $(0.18)$ \\
\hline \multirow[t]{2}{*}{ Used alc. weekly during preg. } & 0.04 & 0.04 & 0.05 & 0.03 & 0.04 \\
\hline & $(0.20)$ & $(0.19)$ & $(0.21)$ & $(0.17)$ & $(0.20)$ \\
\hline Did not smoke during preg. & 0.99 & 0.99 & 0.99 & 0.99 & 0.99 \\
\hline Had a previous c-section & 0.14 & 0.10 & 0.13 & 0.16 & 0.18 \\
\hline Observations & 7496 & 697 & 4937 & 1261 & 601 \\
\hline
\end{tabular}

Sample means/proportions. Standard deviations for continuous variables in parentheses. 
Table 3: OLS Models, all infants

\begin{tabular}{|c|c|c|c|c|c|c|}
\hline VARIABLES & Macrosomia & $\begin{array}{l}\text { Weeks of } \\
\text { Gestation }\end{array}$ & $\begin{array}{l}\text { Low Birth } \\
\text { Weight }\end{array}$ & $\begin{array}{c}\text { Preterm } \\
\text { Birth } \\
\end{array}$ & LGA & SGA \\
\hline Mom $\mathrm{BMI}<18.5$ & $\begin{array}{l}-0.002 \\
(0.005)\end{array}$ & $\begin{array}{c}-0.524 * * * \\
(0.102)\end{array}$ & $\begin{array}{c}0.051 * * * \\
(0.015)\end{array}$ & $\begin{array}{c}0.061 * * * \\
(0.016)\end{array}$ & $\begin{array}{c}-0.032 * * * \\
(0.009)\end{array}$ & $\begin{array}{c}0.065^{* * *} \\
(0.019)\end{array}$ \\
\hline Mom 25<BMI<29.9 & $\begin{array}{c}0.003 \\
(0.004)\end{array}$ & $\begin{array}{c}0.108 \\
(0.069)\end{array}$ & $\begin{array}{c}-0.023 * * * \\
(0.009)\end{array}$ & $\begin{array}{l}-0.011 \\
(0.011)\end{array}$ & $\begin{array}{c}0.025^{* *} \\
(0.010)\end{array}$ & $\begin{array}{c}-0.043 * * * \\
(0.012)\end{array}$ \\
\hline Mom BMI>30 & $\begin{array}{l}0.014^{*} \\
(0.007)\end{array}$ & $\begin{array}{c}0.327 * * * \\
(0.094)\end{array}$ & $\begin{array}{c}-0.041^{* * * *} \\
(0.012)\end{array}$ & $\begin{array}{l}-0.026^{*} \\
(0.015)\end{array}$ & $\begin{array}{c}0.076^{* * *} \\
(0.015)\end{array}$ & $\begin{array}{c}-0.075 * * * \\
(0.017)\end{array}$ \\
\hline GWG & $\begin{array}{c}0.001^{* * *} \\
(0.000)\end{array}$ & $\begin{array}{c}0.017 * * * \\
(0.002)\end{array}$ & $\begin{array}{c}-0.002 * * * \\
(0.000)\end{array}$ & $\begin{array}{c}-0.002 * * * \\
(0.000)\end{array}$ & $\begin{array}{c}0.003 * * * \\
(0.000)\end{array}$ & $\begin{array}{c}-0.003 * * * \\
(0.000)\end{array}$ \\
\hline Constant & $\begin{array}{l}-0.746 \\
(1.557)\end{array}$ & $\begin{array}{c}134.477 * * * \\
(24.744)\end{array}$ & $\begin{array}{l}-6.295 * \\
(3.308)\end{array}$ & $\begin{array}{c}-12.667 * * * \\
(3.995)\end{array}$ & $\begin{array}{c}4.490 \\
(3.402)\end{array}$ & $\begin{array}{c}3.622 \\
(4.387)\end{array}$ \\
\hline Observations & 7,496 & 7,462 & 7,496 & 7,487 & 7,496 & 7,496 \\
\hline R-squared & 0.013 & 0.035 & 0.034 & 0.019 & 0.035 & 0.047 \\
\hline
\end{tabular}

Robust standard errors in parentheses. All models include controls for cigarette and alcohol use during pregnancy as well as income, race, mother's age at first birth, mother's age at current birth, birth order, birth year, mother's education and marital status, and prenatal vitamin use and month of first prenatal visit. Low birth weight refers to infant born less than 5.5 pounds. Pre-term birth refers to infants born before 37 weeks. $* * * \mathrm{p}<0.01, * * \mathrm{p}<0.05, * \mathrm{p}<0.1$ 
Table 4: OLS Models, all infants

\begin{tabular}{|c|c|c|c|c|c|c|}
\hline VARIABLES & $\begin{array}{l}\text { C-section } \\
\text { Birth }\end{array}$ & $\begin{array}{c}\text { \# dr. visits } \\
\text { Infant's first } \\
\text { yr } \\
\end{array}$ & $\begin{array}{c}\text { \# days } \\
\text { Mom in hosp. } \\
\text { Post delivery }\end{array}$ & $\begin{array}{c}\text { Infant was } \\
\text { Breastfed }\end{array}$ & $\begin{array}{c}\text { If breastfed, } \\
\text { weeks } \\
\text { Breastfed } \\
\end{array}$ & $\begin{array}{c}\text { \# days } \\
\text { Infant in hosp } \\
\text { Post delivery }\end{array}$ \\
\hline Mom $\mathrm{BMI}<18.5$ & $\begin{array}{c}-0.019 * \\
(0.010)\end{array}$ & $\begin{array}{l}-0.023 \\
(0.161)\end{array}$ & $\begin{array}{c}0.092 \\
(0.174)\end{array}$ & $\begin{array}{l}-0.017 \\
(0.022)\end{array}$ & $\begin{array}{c}1.626 \\
(1.587)\end{array}$ & $\begin{array}{c}0.220 \\
(0.581)\end{array}$ \\
\hline Mom 25<BMI $<29.9$ & $\begin{array}{c}0.030 * * * \\
(0.011)\end{array}$ & $\begin{array}{c}0.250 \\
(0.164)\end{array}$ & $\begin{array}{c}0.125 \\
(0.123)\end{array}$ & $\begin{array}{c}-0.045^{* * *} \\
(0.017)\end{array}$ & $\begin{array}{l}-1.580 \\
(1.049)\end{array}$ & $\begin{array}{l}-0.024 \\
(0.185)\end{array}$ \\
\hline Mom BMI>30 & $\begin{array}{c}0.082 * * * \\
(0.018)\end{array}$ & $\begin{array}{c}0.374 * * \\
(0.168)\end{array}$ & $\begin{array}{l}0.295^{*} \\
(0.156)\end{array}$ & $\begin{array}{l}-0.033 \\
(0.025)\end{array}$ & $\begin{array}{c}-3.869 * * * \\
(1.392)\end{array}$ & $\begin{array}{l}0.539 * \\
(0.320)\end{array}$ \\
\hline GWG & $\begin{array}{c}0.001 * * * \\
(0.000)\end{array}$ & $\begin{array}{c}0.002 \\
(0.004)\end{array}$ & $\begin{array}{c}0.006 \\
(0.004)\end{array}$ & $\begin{array}{c}0.000 \\
(0.000)\end{array}$ & $\begin{array}{c}-0.079 * * * \\
(0.027)\end{array}$ & $\begin{array}{c}0.006 \\
(0.006)\end{array}$ \\
\hline Mom had prev. c-sec & $\begin{array}{c}0.906 * * * \\
(0.005)\end{array}$ & & & & & \\
\hline Weeks of gestation & $\begin{array}{c}-0.007 * * * \\
(0.001)\end{array}$ & & & & & $\begin{array}{c}-1.171 * * * \\
(0.174)\end{array}$ \\
\hline Low birthweight & & & & & & $\begin{array}{c}6.830 * * * \\
(0.616)\end{array}$ \\
\hline Constant & $\begin{array}{l}-1.629 \\
(3.502)\end{array}$ & $\begin{array}{c}41.398 \\
(43.053)\end{array}$ & $\begin{array}{c}181.399 * * * \\
(42.272)\end{array}$ & $\begin{array}{l}-1.131 \\
(6.280)\end{array}$ & $\begin{array}{l}-237.523 \\
(381.382)\end{array}$ & $\begin{array}{c}279.524 * * * \\
(80.652)\end{array}$ \\
\hline Observations & 7,425 & 7,433 & 7,004 & 7,285 & 3,422 & 7,008 \\
\hline R-squared & 0.582 & 0.014 & 0.022 & 0.174 & 0.065 & 0.194 \\
\hline
\end{tabular}

Robust standard errors in parentheses. All models include controls for cigarette and alcohol use during pregnancy as well as income, race, mother's age at first birth, mother's age at current birth, birth order, birth year, mother's education and marital status, and prenatal vitamin use and month of first prenatal visit. Low birth weight refers to infant born less than 5.5 pounds. Pre-term birth refers to infants born before 37 weeks. $* * * \mathrm{p}<0.01, * * \mathrm{p}<0.05, * \mathrm{p}<0.1$ 


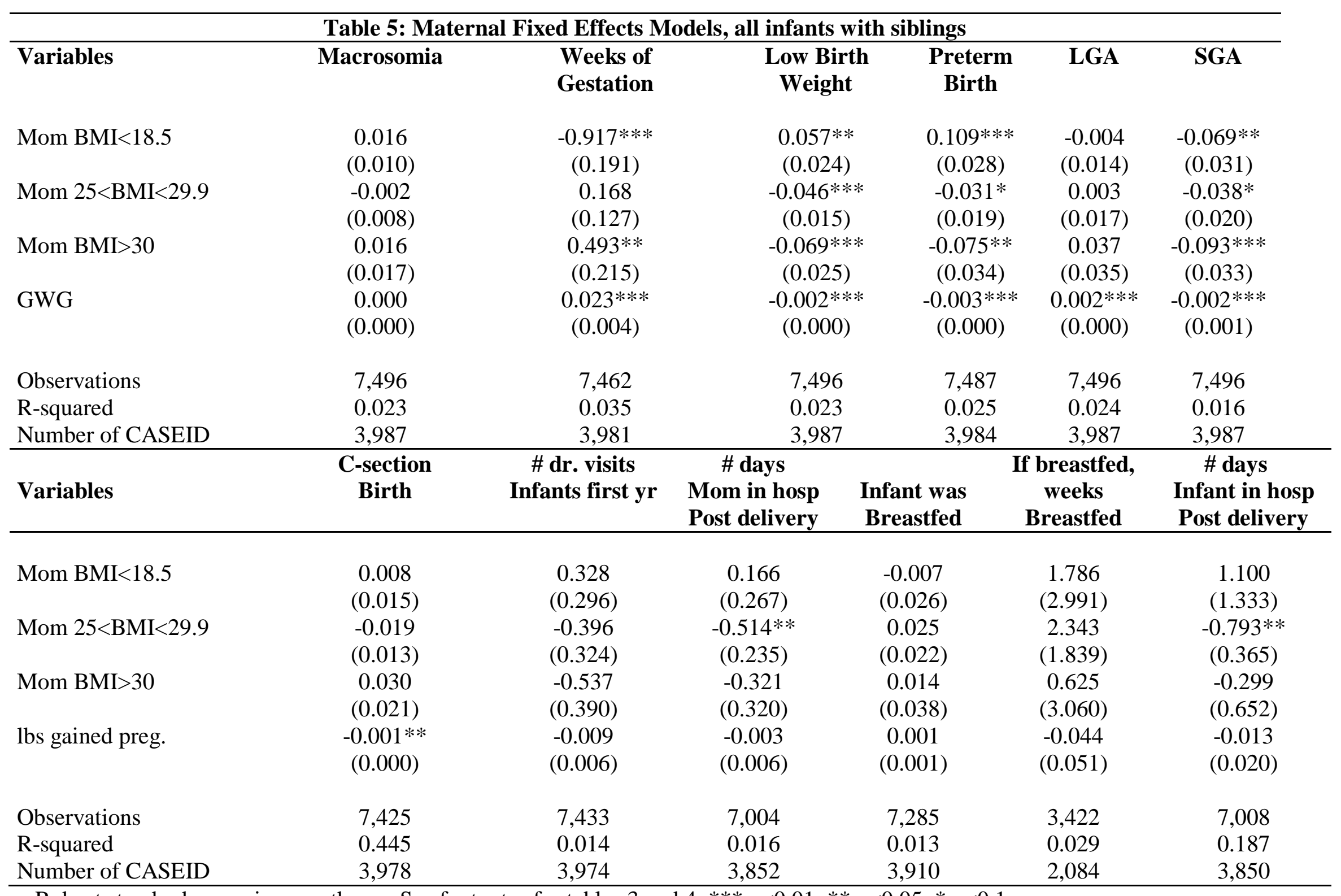

Robust standard errors in parentheses. See footnotes for tables 3 and $4 .{ }^{* * *} \mathrm{p}<0.01,{ }^{* *} \mathrm{p}<0.05,{ }^{*} \mathrm{p}<0.1$ 